\title{
'Does levothyroxine improve pregnancy outcomes in euthyroid women with thyroid autoimmunity undergoing assisted reproductive technology?'
}

Kris Poppe ${ }^{1,3^{*}}$, Flora Veltri ${ }^{1,3}$ and Candice Autin ${ }^{2}$

\begin{abstract}
Evidence on the treatment of euthyroid infertile women and thyroid autoimmunity with thyroid hormone is scare, and therefore the recent study by Wang et al. is a welcome addition to it. Based on their results, thyroid hormone seems not to be indicated to decrease the miscarriage rate in that particular group of infertile women. This comment is meant to put the study results into perspective with the available evidence and the current guidelines, and to highlight its strengths and weaknesses.
\end{abstract}

Keywords: ART, ICSI, IVF, Infertility, Miscarriage, Pregnancy outcome, Thyroid function and autoimmunity

\section{Background}

Thyroid autoimmunity (TAI), defined by the presence of increased levels of anti-thyroid peroxidase antibodies (TPO-abs) and/or anti-thyroglobulin antibodies (Tg-abs) is a frequent finding in the general population $(\sim 10 \%$ depending on the iodine intake of the investigated population), and is even higher in infertile women with polycystic ovaries and idiopathic infertility $(\sim 20-30 \%)[1,2]$. Women with TAI and treated with ovarian hyperstimulation as preparation of an assisted reproductive technology (ART) have a more important (and often definitive) decrease in their thyroid hormone levels compared with women without TAI [3]. Finally, the presence of TAI is associated with an increased risk of a first trimester miscarriage, and a number of reasons for that association have been proposed $[4,5]$. Compared with women without TAI, women with TAI are older, have more often concomitant autoimmune disorders (reflected by the presence of anticardiolipin, antinuclear, or lupus anticoagulants), may have an immune imbalance of which thyroid antibodies are markers, and finally do they have mild thyroid hypofunction that subsequently

\footnotetext{
* Correspondence: kris_poppe@stpierre-bru.be

${ }^{1}$ Endocrine Unit Centre Hospitalier Universitaire Saint Pierre, Rue Haute 322 1000 Brussels, Belgium

${ }^{3}$ Université Libre de Bruxelles (ULB), 1050 Brussels, Belgium

Full list of author information is available at the end of the article
}

creates a less favourable environment, impairing the in-vitro embryo development and/or the early phase of implantation [6]. Taking into consideration the latter hypothesis, a research question is whether thyroid hormone treatment (LT4) could overcome this relative thyroid dysfunction caused by TAI?

\section{Main text}

In this randomized clinical trial, treatment with LT4 in euthyroid infertile women with TAI and treated with ART (IVF (in-vitro fertilization) or ICSI (intra-cytoplasmic sperm injection)) did not reduce the miscarriage rate before 28 weeks' gestation compared with placebo (10.3\% versus $10.6 \%)$ [7].

Strengths of the study were the large number of patients included (all with TPO-abs), and the exclusion of women with other auto-immune antibodies, such as anticardiolipin, antinuclear and lupus anticoagulants. Women in both study groups received the same ovarian stimulation protocols, and the number of (fresh) embryos transferred was comparable. Finally, the initiation of LT4 before the ovarian stimulation procedure (i.e. before pregnancy) and the titration of the LT4 dosage during pregnancy to obtain TSH levels within trimester-specific reference ranges were additional strengths and an amelioration compared with previous studies in the field [7].

(c) The Author(s). 2018 Open Access This article is distributed under the terms of the Creative Commons Attribution 4.0 International License (http://creativecommons.org/licenses/by/4.0/), which permits unrestricted use, distribution, and reproduction in any medium, provided you give appropriate credit to the original author(s) and the source, provide a link to the Creative Commons license, and indicate if changes were made. The Creative Commons Public Domain Dedication waiver (http://creativecommons.org/publicdomain/zero/1.0/) applies to the data made available in this article, unless otherwise stated. 
Before the study by Wang et al., evidence on LT4 treatment in infertile women with TAI was limited to a few studies with negative outcomes, however, these studies were subject to a number of important limitations $[8,9]$. In the study by Negro et al., a non-significant difference in the miscarriage rate was noted (in favour of the LT4 group), but it was underpowered and subject to a type II statistical error [8]. The study by Revelli et al. was retrospective, and three different types of medications were given (LT4, acetyl-salicylic acid, and prednisolone) in a non-randomised way, and only a small number of patients were included [9]. Based on those two studies, the American Thyroid Association (ATA) guidelines on the management of thyroid disorders during pregnancy found the evidence insufficient to determine whether LT4 therapy improves the success of pregnancy following ART in euthyroid women with TAI, however, it is mentioned that 25-50 $\mu \mathrm{g}$ LT4 may be considered given its potential benefits compared to its minimal risk [10].

The results of the study by Wang et al. might weaken this ATA recommendation, but "let's not throw the (LT4) baby out with the bathwater". Before concluding that LT4 is not effective to reduce miscarriage rates in euthyroid women with TAI, we believe the study results should be put in perspective with the current evidence and thoroughly analysed.

The incidence of miscarriage in clinically pregnancies ( $<20$ gestational weeks) is $8-20 \%$, and in case of the presence of TAI, it is up to $30 \%$ (4). Taking this into consideration, $\sim 10 \%$ miscarriage rate in this study reduces its power.

A few years ago in a meta-analysis on the association between TAI and pregnancy outcomes after ART, an increased risk for a first trimester miscarriage was observed compared with that in women without TAI [4]. The odds ratio (OR) in that study was 3.15 , while in a recent meta-analysis on the same association, the OR was only 1.44 [5]. Two important reasons can be put forward for that decreasing OR, and at the same time, they might explain (partially) the negative results in the study by Wang et al. A first reason can be the increased use of ICSI as type of ART, since ICSI can bias the impeding effects of thyroid antibodies in the follicular fluid on the fertilization of the egg, and therefore, be the more accurate type of ART in women with TAI [11]. Indeed, in a recent meta-analysis, infertile women with TAI and all treated with ICSI (but not with LT4), had comparable miscarriage (and live birth) rates as women without TAI [12]. In the study by Wang et al. the prevalence of women treated with ICSI was $\sim 45 \%$ in both study groups. Another important point is the changed definition of a normal thyroid function and subclinical hypothyroidism $(\mathrm{SCH})$ over the years. In the studies performed before 2010, a normal thyroid function during the first trimester of pregnancy was defined as a serum TSH level within the upper limit of the assay (often $<4$ to 5 $\mathrm{mIU} / \mathrm{L}$ ), while for the period 2010-2016, it was $<2.5$ $\mathrm{mIU} / \mathrm{L}[10,13]$. The lower upper limit in the more recent studies might be a reason why the presence of TAI was not anymore associated with altered ART outcomes, as it was shown in a number of recent studies [14-16].

ICSI and LT4 treatments can also be complementary and improve pregnancy outcomes; ICSI on the in-vitro outcomes, and LT4 by preserving a normal thyroid function during pregnancy. Therefore, it make sense that the negative results in the observational studies on the impact of TAI in infertile women with TSH levels within pregnancy-specific reference range (usually $\sim 4.0-4.5$ $\mathrm{mIU} / \mathrm{L}$ ) and mainly treated with ICSI are in some way predictive for negative study results in interventional trials, and more in particular in that by Wang et al. [7].

In their discussion, the authors also mention that in a pooled analysis of 3 randomized clinical trials, LT4 treatment on pregnancy outcomes among women with TAI and a normal thyroid function significantly decreased the miscarriage rate (RR:0.45; 95\% CI, 0.24-0.82) [17]. However, in two of the three studies in that meta-analysis (> $60 \%$ of all women included), serum TSH levels were $>4.0$ to $4.5 \mathrm{mIU} / \mathrm{L}$ and thus compatible with $\mathrm{SCH}$ and not a normal thyroid function. In study by Wang et al., normal thyroid function was defined as a serum TSH $<4.7 \mathrm{mIU} /$ L. Indeed, in the 2017 ATA guidelines, LT4 treatment for women with TPO-abs and a serum TSH above pregnancy-specific reference range (or $>4.0 \mathrm{mU} / \mathrm{L}$ if unavailable) is strongly recommended [10].

In most studies, the diagnosis of TAI is based on the presence of TPO-abs only [10]. However, in a prospective study determining the presence of TAI in infertile women, only positivity for $\mathrm{Tg}$-abs was more frequent compared with that of TPO-abs [18]. In the same study, women with only Tg-abs also had higher mean serum TSH levels compared with women with only TPO-abs, and in a recent study in China, women with Tg-abs had higher miscarriage rates compared with women with TPO-abs [19]. Not testing for Tg-abs may therefore lead to misclassification, modify study conclusions and impair the management of pregnant women. The importance of Tg-abs is now also noticed in the ATA guidelines on the management of thyroid disorders during pregnancy [10]. Concerning the currently used cut-off for TPO-ab positivity, a recent study highlights that it may be too high. The authors found a dose-dependent relationship between TPO-ab levels and TSH as well as the risk of premature delivery, and therefore, the use of a population-based, pregnancy-specific, functional cut-off for TPO-abs may be useful in the future [20].

\section{Conclusions}

Before recommending against LT4 treatment in infertile women with TAI and serum TSH levels within 
pregnancy-specific reference range, we believe that more studies are needed investigating the impact of thyroid function/TAI and ICSI on the in-vitro data (oocyte quality, fertilization rate, embryo quality), the optimal LT4 dosage, and finally, optimising the diagnosis of TAI e.g. by taking $\mathrm{Tg}$-abs into account as an equal marker as positivity for TPO-abs. In the meantime, physicians should judge case by case whether LT4 should be given, taking into account other parameters such as baseline serum TSH levels, the obstetric history of the women, and the cause of the infertility in the couple, with a particular attention in case of female and idiopathic infertility.

\section{Abbreviations}

ART: Assisted reproductive technology; ATA: American Thyroid Association; ICSI: Intra-cytoplasmic sperm injection; IVF: In-vitro fertilization; LT4: Levothyroxine; SCH: Subclinical hypothyroidism; TAl: Thyroid autoimmunity; Tg-abs: Thyroglobulin antibodies; TPO-abs: Thyroid peroxidase antibodies

\section{Authors' contributions}

KP wrote the commentary, FV and CA gave additional comments and/or proposed changes. All authors read and approved the final manuscript.

\section{Ethics approval and consent to participate}

Not applicable.

\section{Competing interests}

Kris Poppe reports speaker fees the IBSA Institut Biochimique SA (satellite meeting of the European Thyroid Association) in 2016 and the Berlin-Chemie AG company (ETA educational thyroid meeting) in 2017. The other authors (CA, FV) declare no support from any organization.

\section{Publisher's Note}

Springer Nature remains neutral with regard to jurisdictional claims in published maps and institutional affiliations.

\section{Author details}

'Endocrine Unit Centre Hospitalier Universitaire Saint Pierre, Rue Haute 322, 1000 Brussels, Belgium. ${ }^{2}$ Departement of Gynecology, Obstetrics, and Reproductive Medicine Unit Centre Hospitalier Universitaire Saint Pierre, Rue Haute 322, 1000 Brussels, Belgium. ${ }^{3}$ Université Libre de Bruxelles (ULB), 1050 Brussels, Belgium.

Received: 19 March 2018 Accepted: 24 May 2018

Published online: 30 May 2018

\section{References}

1. Poppe K, Velkeniers B, Glinoer D. The role of thyroid autoimmunity in fertility and pregnancy. Nat Clin Pract Endocrinol Metab. 2008;4:394-405.

2. van den Boogaard E, Vissenberg R, Land JA, van Wely M, van der Post JA, Goddijn M, et al. Significance of (sub)clinical thyroid dysfunction and thyroid autoimmunity before conception and in early pregnancy: a systematic review. Hum Reprod Update. 2011;17:605-19.

3. Busnelli A, Somigliana E, Ferrari S, Filippi F, Vannucchi G, Fugazzola L, et al. The long-term impact of controlled ovarian Hyperstimulation on thyroid function. Endocr Pract. 2016;22:389-95.

4. Thangaratinam S, Tan A, Knox E, Kilby MD, Franklyn J, Coomarasamy A. Association between thyroid autoantibodies and miscarriage and preterm birth: meta-analysis of evidence. BMJ. 2011;342:d2616.

5. Busnelli A, Paffoni A, Fedele L, Somigliana E. The impact of thyroid autoimmunity on IVF/ICSI outcome. Hum Reprod Update. 2016;22:775-90.

6. Krassas GE, Poppe K, Glinoer D. Thyroid function and human reproductive health. Endocr Rev. 2010;31:702-55.

7. Wang H, Gao H, Chi H, Zeng L, Xiao W, Wang Y, et al. Effect of levothyroxine on miscarriage among women with normal thyroid function and thyroid autoimmunity undergoing in vitro fertilization and embryo transfer: a randomized clinical trial. JAMA. 2017;318:2190-8.
8. Negro R, Mangieri T, Coppola L, Presicce G, Casavola EC, Gismondi R, et al. Levothyroxine treatment in thyroid peroxidase antibody-positive women undergoing assisted reproduction technologies: a prospective study. Hum Reprod. 2005:20:1529-33.

9. Revelli A, Casano S, Piane LD, Grassi G, Gennarelli G, Guidetti D, et al. A retrospective study on IVF outcome in euthyroid patients with anti-thyroid antibodies: effects of levothyroxine, acetyl-salicylic acid and prednisolone adjuvant treatments. Reprod Biol Endocrinol. 2009;7:137.

10. Alexander EK, Pearce EN, Brent GA, Brown RS, Chen H, Dosiou C, et al. 2017 guidelines of the American Thyroid Association for the diagnosis and management of thyroid disease during pregnancy and the postpartum. Thyroid. 2017:27:315-89.

11. Monteleone P, Parrini D, Faviana P, Carletti E, Casarosa E, Uccelli A, et al. Female infertility related to thyroid autoimmunity: the ovarian follicle hypothesis. Am J Reprod Immunol. 2011;66:108-14.

12. Poppe K, Autin C, Veltri F, Kleynen P, Grabczan L, Rozenberg S, et al. Thyroid autoimmunity and intracytoplasmic sperm injection outcome: a systematic review and meta-analysis. J Clin Endocrinol Metab. 2018;103:7155-66.

13. De Groot $L$, Abalovich M, Alexander EK, Amino N, Barbour L, Cobin RH, et al. Management of thyroid dysfunction during pregnancy and postpartum: an Endocrine Society clinical practice guideline. J Clin Endocrinol Metab. 2012; 97:2543-65.

14. Lukaszuk K, Kunicki M, Kulwikowska P, Liss J, Pastuszek E, Jaszczołt M, et al. The impact of the presence of antithyroid antibodies on pregnancy outcome following intracytoplasmatic sperm injection-ICSI and embryo transfer in women with normal thyreotropine levels. J Endocrinol Investig. 2015;38:1335-43.

15. Mintziori G, Goulis DG, Gialamas E, Dosopoulos K, Zouzoulas D, Gitas G, Venetis CA, et al. Association of TSH concentrations and thyroid autoimmunity with IVF outcome in women with TSH concentrations within normal adult range. Gynecol Obstet Investig. 2014;77:84-8.

16. Unuane D, Velkeniers B, Deridder S, Bravenboer B, Tournaye H, De Brucker M. Impact of thyroid autoimmunity on cumulative delivery rates in in vitro fertilization/intracytoplasmic sperm injection patients. Fertil Steril. 2016;106: 144-50.

17. Velkeniers B, Van Meerhaeghe A, Poppe K, Unuane D, Tournaye H, Haentjens P. Levothyroxine treatment and pregnancy outcome in women with subclinical hypothyroidism undergoing assisted reproduction technologies. Hum Reprod Update. 2013;19:251-8.

18. Unuane D, Velkeniers B, Anckaert E, Schiettecatte J, Tournaye H, Haentjens P, Poppe K. Thyroglobulin autoantibodies: is there any added value in the detection of thyroid autoimmunity in women consulting for fertility treatment? Thyroid. 2013;23:1022-8.

19. Liu H, Shan Z, Li C, Mao J, Xie X, Wang W, et al. Maternal subclinical hypothyroidism, thyroid autoimmunity, and the risk of miscarriage: a prospective cohort study. Thyroid. 2014;24:1642-9.

20. Korevaar TIM, Pop VJ, Chaker L, Goddijn M, de Rijke YB, Bisschop PH, et al. Dose dependency and a functional cutoff for TPO-antibody positivity during pregnancy. J Clin Endocrinol Metab. 2018;103:778-89.

\section{Ready to submit your research? Choose BMC and benefit from:}

- fast, convenient online submission

- thorough peer review by experienced researchers in your field

- rapid publication on acceptance

- support for research data, including large and complex data types

- gold Open Access which fosters wider collaboration and increased citations

- maximum visibility for your research: over $100 \mathrm{M}$ website views per year

At BMC, research is always in progress.

Learn more biomedcentral.com/submissions 